Check for updates

Cite this: J. Anal. At. Spectrom., 2021 36, 813

Received 27th January 2021 Accepted 18th March 2021

DOI: 10.1039/d1ja00032b

rsc.li/jaas

\section{Classification of minerals and the assessment of lithium and beryllium content in granitoid rocks by laser-induced breakdown spectroscopy}

\author{
Patrick Janovszky, ab Krisztián Jancsek, ${ }^{c}$ Dávid J. Palásti, ${ }^{\text {ab }}$ Judit Kopniczky, ${ }^{d}$ \\ Béla Hopp, iD bd Tivadar M. Tóth iD c and Gábor Galbács iD *ab
}

\begin{abstract}
This study demonstrates that LIBS mapping and spatially resolved local analysis is an efficient and practical approach for the classification of mineral grains (quartz, feldspar, biotite, amphibole) and for prospecting of technologically relevant, low-Z elements (e.g. Be and Li) in granitoid rock samples. We tested three statistical approaches (classification tree (CT) based on indicator elements, linear discriminant analysis (LDA) and random forest (RF)) for the classification of the mineral grains and found that each of the three methods provides fairly similar, very good classification accuracies. RF and LDA provided better than $92 \%$ accuracy for all minerals, whereas CT showed a somewhat poorer (around 80\%) accuracy for quartz in particular. Our results also demonstrate that using multiple analytical locations within each grain and resting the classification on the majority vote of these individual analysis gives more reliable discrimination (grain-based accuracy is better than location-based accuracy). We also demonstrated that LIBS elemental mapping can provide valuable information about the distribution of chemical elements among the minerals, especially if it is combined with matrix-matched calibration of emission intensity data. We illustrated this by the successful assessment of $\mathrm{ng}$ to $\mu \mathrm{g}$ amounts of $\mathrm{Be}$ and $\mathrm{Li}$ in the studied mineral grains. Our results suggest that mining for Be and $\mathrm{Li}$ in granitoid rocks should be aiming for biotite and amphibole grains.
\end{abstract}

\section{Introduction}

As it is known, LIBS is a versatile, laser ablation-based atomic emission spectroscopy technique, which allows the fast and direct analysis of solid and liquid (even gaseous) samples with minimum sample preparation, in a non-contact, marginally destructive way. ${ }^{\mathbf{1 - 3}}$ Its routine configuration already makes trace (ppm level) elemental analysis possible for all elements of the periodic table, but more sophisticated laboratory setups (e.g. in double- or multi-pulse configurations) can even provide ppbrange detection limits. ${ }^{\mathbf{1 4}}$ Time-resolved analysis of the plasma emission also permits isotope-selectivity. ${ }^{5}$ There is ample demonstration in the literature that the feature-rich LIBS spectra can be successfully used for the accurate identification or discrimination of a variety of samples (chemical fingerprinting). ${ }^{6-11}$ Micrometer-resolution local analysis or elemental

\footnotetext{
${ }^{a}$ Department of Inorganic and Analytical Chemistry, University of Szeged, Dóm Square 7, 6720 Szeged, Hungary.E-mail: galbx@chem.u-szeged.hu

${ }^{b}$ Department of Materials Science, Interdisciplinary Excellence Centre, University of Szeged, Dugonics Square 13, 6720 Szeged, Hungary

'Department of Mineralogy, Geochemistry and Petrology, University of Szeged, Egyetem Street 2, 6720 Szeged, Hungary

${ }^{d}$ Department of Optics and Quantum Electronics, University of Szeged, Dóm Square 9, 6720 Szeged, Hungary
}

mapping can also be done on solid samples, allowing for material science, medical, environmental or industrial applications, ${ }^{\mathbf{1 - 3 , 9 , 1 2 - 1 4}}$ even in the field.

One of the most appealing characteristics of LIBS is the possibility of direct solid sample analysis, which makes it of interest also to geologists and mineralogists. In this context, the analytical performance and package of attributes of LIBS have often been compared to those of other spatially resolving solid sampling atomic spectroscopy techniques. Although it is not a perfect analytical technique, but LIBS does offer a uniquely advantageous combination of features. For example, laser ablation inductively coupled plasma mass spectrometry (LAICP-MS), which has several decades of success in geology, has a similar overall analytical potential, but is not portable, cannot be used in a stand-off configuration, struggles with the detection of some lighter elements and has challenges in the quantitative analysis due to issues related to the need for the transportation of ablated sample matter. Micro X-ray fluorescence spectrometry ( $\mu$-XRF) is a popular desktop instrument in geochemical elemental analysis, but in contrast to LIBS it cannot sensitively detect low- $Z$ elements (below $\mathrm{Na}$ ), it has a narrower dynamic range, its spectra contain far less chemical information and it cannot be used remotely. Electron-probe micro analyzers (EPMA, similar to SEM-EDS or SEM-WDS) can provide very high spatial resolution and an elemental map 
within a very short time, but require tedious sample preparation and vacuum-ready samples and are very bulky and costly instruments. In addition they are not capable for measuring light elements or in the field or stand-off, and have quite limited accuracy and dynamic range. ${ }^{\mathbf{1 , 1 5 - 1 7}}$

Based on the above-discussed aspects, it is no wonder that LIBS is being increasingly explored by geologists and the mining and mineral processing industry in the last 10-15 years and is now more and more used for the analysis of geological material (GEOLIBS). ${ }^{15,16,18}$ A further, highly related, although more specialized application is planetary exploration using the LIBS instrumentation in the ChemCam system of the Curiosity Mars rover. ${ }^{9,19,20}$

LIBS geochemical analysis is generally directed towards one or the other of two primary and related goals: quantitative analysis of the elemental contents of rocks/minerals (e.g. ore prospecting) and identification of the minerals (e.g. mapping of geochemical and mineralogical footprints, provenance analysis). For example, LIBS measurements with field-applicable bespoke or laboratory-based instrumentation were successfully demonstrated for the compositional analysis of silicate and carbonate minerals, ${ }^{21,22}$ iron and phosphate ores, ${ }^{23-25}$ speleothems, ${ }^{26,27}$ monazite sand, ${ }^{28}$ volcanic rocks, ${ }^{29,30}$ soils, ${ }^{31}$ fluid inclusions $^{32}$ and other materials. In these studies, the concentration of several elements including $\mathrm{Au}, \mathrm{Fe}, \mathrm{Cu}, \mathrm{Zn}, \mathrm{Pb}, \mathrm{Ca}, \mathrm{Mg}$, $\mathrm{Sr}, \mathrm{Mn}, \mathrm{Si}, \mathrm{Cr}, \mathrm{Al}, \mathrm{K}, \mathrm{REEs}$, etc. were assessed by using principal components analysis (PCA), multivariate regression (PCR), artificial neural network (ANN) analysis or partial least-squares regression (PLSR) for the construction of calibration models. Either drill-core or ground rock samples were tested. In both cases, a large number of measurements are carried out to provide stratification or average concentration data. ${ }^{15,16,18}$ Another important field, where the on-site quantitative analysis of natural solid resources is needed and LIBS has already proven itself useful is the energy industry, more precisely coal analysis. For instance, the LIBS determination of carbon content, volatile content and the calorific value was shown to be practical and accurate enough ${ }^{33,34}$ so that this information to be used for fuel type discrimination or control of coal-fueled power plants.

Mineral and rock type identification also necessitates the use of statistical data analysis. Broad discrimination of ore mineralogy by PCA was demonstrated in selected wavelength windows in Australian iron ores. ${ }^{23}$ Porrízka et al. also used PCA to classify 27 igneous rock samples. ${ }^{35}$ In another study, PCA and soft independent modelling of class analogy (SIMCA) methods were used to generate a model and predict the type of samples. ${ }^{36}$ Harmon et al. used a spectral library approach to rapidly identify and classify samples based on their dominant elements with a high degree of confidence. It was observed that a maximum variance weighted - maximum correlation approach performs best. Minerals of different classes were correctly identified at a success rate of $>95 \%$ for carbonates and $>85 \%$ for feldspars and pyroxenes. ${ }^{37}$ PCA and partial least squares discriminant analysis (PLS-DA) were used by Gottfried et $a .^{38}$ to identify the distinguishing characteristics of geological samples and to classify them based on their minor impurities. The PLS-DA approach was later successfully extended to the provenance analysis of garnets, ${ }^{39}$ obsidian glasses, ${ }^{40}$ igneous and sedimentary rocks ${ }^{9}$ as well as conflict minerals (e.g. columbite and tantalite). ${ }^{41}$ Most recently, the application of the advanced spectral angle mapper algorithm (SAM) for the identification of variations in the chemical composition in a complex chromite ore sample was also successfully demonstrated by Meima and Rammlmair. ${ }^{42}$ Nardecchia et al. introduced a new, LIBS-based spectral analysis strategy and named it embedded $k$-means clustering, for the simultaneous detection of major and minor compounds and the generation of associated localization maps for the characterization of complex and heterogeneous rock samples at the micro-scale level. ${ }^{\mathbf{4 3}}$

The above examples only illustrate the unique analytical potential of LIBS in geology-related or raw material exploration applications. This potential is expected to unfold in the coming years and more and more industrial, green-field or brown-field (mine), stand-off LIBS applications will be developed. This development is also propelled by the increased demand and declining reserves for raw materials needed by advanced technologies. Two of the metals that are in high demand in recent years are Li and Be. Beryllium is widely used, e.g. in telecommunications infrastructure, advanced medical diagnostics instrumentation, automobile components and aeroplane equipment. Lithium is also a greatly sought-after metal, as it is used in large amounts in batteries, ceramics and glass, lubricating greases and polymer production. The uneven distribution and limited availability made critical raw materials to be a subject of geopolitics and made the governments and companies $^{\mathbf{4 4 , 4 5}}$ realize that the mineral industry has to adopt new, cost-effective methodologies and technologies. LIBS is one of the promising and flexible novel exploration tools, considering its sensitivity towards all elements, speed, informationrich spectra, as well as field- and stand-off applicability. ${ }^{15}$

In the present study, we assess the potential of LIBS for the identification of minerals (biotite, feldspar, quartz and, partially, amphibole) and the distribution and quantitative amount of lithium and beryllium in granitoid rock samples. The pros and cons of several analytical and data evaluation approaches are discussed and tested.

\section{Experimental}

\subsection{Instrumentation}

LIBS experiments were performed on a J-200 Tandem LA/LIBS instrument (Applied Spectra, USA), in the LIBS mode. This instrument is equipped with a $266 \mathrm{~nm}, 6 \mathrm{~ns} \mathrm{Nd}$ :YAG laser source and a six-channel CCD spectrometer with a resolution of $0.07 \mathrm{~nm}$. For every laser shot, the full LIBS spectra over the wavelength range of 190 to $1040 \mathrm{~nm}$ were recorded in the Axiom data acquisition software, using a $0.5 \mu$ s gate delay and $1 \mathrm{~ms}$ gate width. During the experiments, a $40 \mu \mathrm{m}$ laser spot size was maintained, as it allows for the sampling of submillimetre grains (small pieces of minerals making up a rock) at several locations, but is large enough to provide ample LIBS signal for trace element detection. The pulse 
energy was generally set at $17.5 \mathrm{~mJ}$ and the laser repetition frequency was $10 \mathrm{~Hz}$. The number of repeated measurements in one sampling location (without translation) was ten. The first shots were clean-up shots, so the spectra originating from them were discarded. Measurements were performed at 4-5 sampling points in each mineral grain (sampling was done in a total of 128 locations for biotite, 155 for feldspar, 83 for quartz and 4 for amphibole). LIBS experiments were carried out under argon, continuously rinsing the ablation cell with a gas flow rate of $1 \mathrm{~L} \mathrm{~min}{ }^{-1}$. Argon gas increases the signal intensities and the continuous flow decreases the fallout of ablation debris around at the crater.

Contact profilometry measurements performed on a Veco Dektak 8 Advanced Development Profiler. The tip had a radius of curvature of $2.5 \mu \mathrm{m}$ and the force applied to the surface during scanning was $30 \mu \mathrm{N}$. The horizontal resolution was set to $0.267 \mu \mathrm{m}$ and $3.175 \mu \mathrm{m}$ in the $x$ and $y$ scan directions, respectively. The vertical resolution was $40 \AA$ A.

Optical images of the rock samples were taken with an Olympus BX-43 microscope equipped with an Olympus DP-73 camera, under polarised and transmitted light.

\subsection{Materials}

2.2.1. Samples. Three samples (M1, M2, M3) were taken from different locations within the Mórágy Granite rock for the study. The main mass of the Mórágy Hills belongs to the Eastern Mecsek Mountains of Hungary and consists of monzogranite, with monzonite inclusions crosscut by leucocratic dykes. At places, the igneous body has a foliated structure as it was affected by ductile deformation and metamorphic overprint. The minor outcrop of the formation is known in the western part of the Mecsek as well. According to recent studies, the age of the formation is 310-320 million years according to $\mathrm{K}-\mathrm{Ar}$ as well as zircon U-Pd geochronology. ${ }^{46}$ The rock types of the Mórágy Granite Formation can be divided into four main groups: monzogranite (typical granitoid rocks); hybrid rocks; monzonite (dark in colour and rich in magnesium and ironbearing minerals) and leucocratic (light) dykes of different compositions. A continuous transition is induced by the hybrid rocks along the zone between the larger-sized monzonite realms and the host granitic rocks, which formed by the mixing of the two types of melt. ${ }^{46,47}$

Our studied samples are of the monzogranite type, i.e. a granite variant with $35-65 \%$ feldspar. The fact that two different feldspars appear in the rock (orthoclase (K-rich) and plagioclase (Na-rich) feldspars) suggests that it had crystallized from magma saturated with water. Besides the two feldspars, the Mórágy Granite contains the most common rock-forming minerals, quartz, biotite and, to a lesser extent, amphibole.

2.2.2. Standards. During the calibration and the examination of matrix effects related to the minerals, various standards were employed. These included the NIST 610, 612 and 614 type glass reference materials, as well as biotite (biotite mica-Fe, from the massif of Saint-Sylvestre, France, provided by the Centre de Recherches Pétrographiques et Géochimiques (CRPG)) and feldspar (JF-1 1985 Ohira feldspar Nagiso-machi,
Nagano Prefecture, Japan, provided by the Geological Survey of Japan (GSJ)) standards.

\subsection{Methods}

2.3.1. Sample preparation and reference mineral identification. The rock samples were prepared for investigations in such a way that from each sample, a $30 \mu \mathrm{m}$ thin section was cut for mineral identification by optical microscopy and the remaining part of the bulk sample (originally in contact with the material of the thin section) was polished for LIBS analysis. This approach ensured that the rock surface submitted to LIBS analysis contained the same mineral grains which were identified.

The cutting was done using a diamond cutter (Struers DiscoPlan) to form $35 \times 20 \times 10 \mathrm{~mm}$ rectangular bodies. These then underwent vacuum impregnation using ARALDITE AY103 and REN HY956 epoxy resins in a Struers CitoVac equipment. After a full day of setting, a fresh surface was created on the impregnated rock body using the diamond cutter. The surface was ground using a Struers LaboPol-35 machine equipped with 80, 220, 500 and 1200 grit Struers MD-Piano diamond grinding wheels. As a final step, the aqueous suspension of $\mathrm{SiC}$ abrasive powder (Buehler) was applied to smoothen the sample surface. $30 \mu \mathrm{m}$ thin sections of these rock bodies were cut using a Buehler PetroThin cutting and grinding machine. The thin sections were mounted on microscope slides using EpoFix epoxy resin. After 24 hours the samples were ready for optical microscopy. The mineral grains within the thin sections were identified and categorized under polarized light using optical microscopy, according to the standardized methods of petrology. ${ }^{48}$ The remaining part of the prepared rock body (bulk) was used for the LIBS measurements.

A reasonable number of the four most common mineral grains in each sample were identified, labelled and numbered in the samples (Fig. 1). The total set of mineral grains in the three samples consisted of 33 biotite, 27 feldspar, 22 quartz grains and a single amphibole grain. Plagioclase and potassium feldspar grains were not distinguished.

\subsection{Data evaluation}

2.4.1. Random forest (RF). A random forest is a classifier that consists of a collection of tree-structured classifiers, where each decision tree, formed on random subset of variables, casts a vote for one of the input classes. The classification is based on their consensus. The prediction power of the RF is often optimized by minimizing the so-called out-of-bag error (OOB error), which gives the percentage of false classifications among the excluded subset of the training data. The two most important parameters of the random forest are the number of the trees grown, and the number of nodes in each tree. The OOB error usually declines with the increase of the number of trees, but the usage of too many trees it is not advisable as it would represent overfitting. The node number indicates the splits, what every individual tree possesses; their number must be equal or larger than $k-1$, where $k$ is the number of groups. ${ }^{49,50}$ 

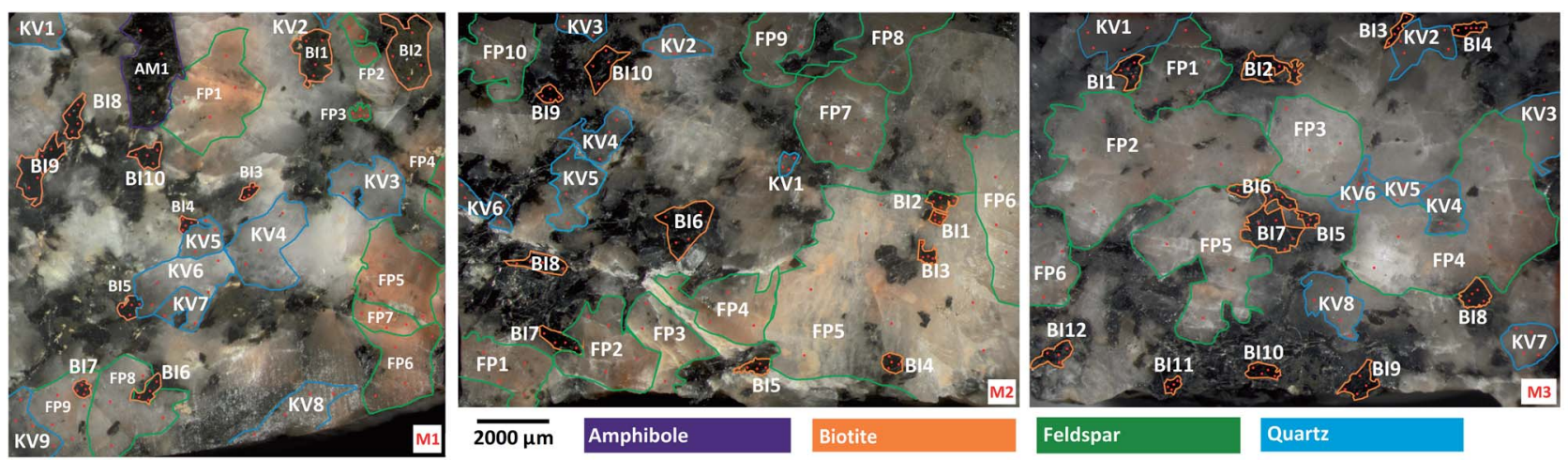

Fig. 1 Reflective optical microscopy images of the rock samples M1, M2 and M3 (Mórágy). The four studied mineral types are indicated in the images with abbreviations and borderline colours: $\mathrm{AM}=$ amphibole (purple), $\mathrm{BI}=$ biotite (orange), $\mathrm{FP}=$ feldspar (green), KV = quartz (blue). Individual laser sampling locations are indicated by red dots.

2.4.2. Linear discriminant analysis (LDA). During linear discriminant analysis $n$ objects (spectra) are separated into $k$ groups (samples) according to their $m$ variables (spectral intensities). There are two different approaches to perform LDA, the so-called Bayesian and Fisher approaches, and the former one was applied in our study. The Bayesian approach assumes a multivariate normal distribution of every variables, and a prior probability $\left(p_{1}+p_{2}+\ldots+p_{n}=1\right)$ is assigned to every group. The posterior probability is calculated by using the equation below. The group where an object belongs is selected based on the similarity of these posterior probabilities. ${ }^{51}$

$$
P(i / x)=\frac{f_{i(x)} p_{i}}{\sum_{j=1}^{k} f_{j(x)} p_{j}}
$$

2.4.3. Nelder-Mead simplex algorithm. The simplex algorithm is a geometry-based approach for function optimization. It defines a scalable $n+1$-point polygon (simplex) for the $n$ parameter function to be optimized and essentially moves this polygon across the response surface of the function. The function is first evaluated at each of the initial apex points of the polygon and it is established which is the edge of the polygon that is adjacent to the lowest values (for minimization). Then, the polygon is geometrically mirrored onto this edge and scaled up or down depending on how large the function value difference was between the largest and smallest one in the preceeding simplex. This approach moves the polygon so that it zeroes in on the location of the extreme value of the function. ${ }^{52}$ As with any function optimization, it is important also with the simplex method to have a good estimate for the initial coordinates of the polygon in order to avoid finding a local minimum instead of a global one.

Spectral line identification was carried out using version 18.0 of the built-in Clarity Software (Applied Spectra, USA) of the LIBS instrument. Data processing was done mainly in the opensource RStudio Desktop software package (v1.3), via developing custom codes using the chemometrics, MASS, ALS, RPart and random forest modules of RStudio. The Nelder-Mead simplex optimization algorithm was programmed and applied in MS Quick Basic programming language. The Image Lab software (Epina, Austria) was used to visualize LIBS elemental maps, whereas the open access ImageJ software was used to extract the surface area of mineral grains in microscopy images of the rock samples. The overall LIBS dataset submitted to RF and LDA contained as many as $12288 \times 370=4546560$ data points.

\section{Results and discussion}

\subsection{Compositional heterogeneities of the mineral grains}

Most mineral grains in igneous rocks grow during a longer time under various physical (first of all pressure and temperature) circumstances and changing chemical conditions resulting in internal chemical zoning patterns. This is, from a chemical point of view, the manifestation of spatial changes of the composition inside a grain. The two most common types of zoning patterns are concentric and sector zoning, but other types, such as patchy, oscillatory, step and others also occur. ${ }^{53,54}$ These changes in chemical composition usually can be detected by different optical methods (e.g. Nomarski Differential Interference Contrast (NDIC) microscopy, cathodoluminescence (CL), etc.), if the compositional changes also induce changes in the optical properties, or by scanning elemental mapping techniques (e.g. electron microprobe (EMP), secondary ion mass spectrometry (SIMS), proton microprobe (PIXE), etc.).${ }^{53}$ Minerals of magmatic rocks, such as the granitoid rocks studied here, are usually zoned. Although the lateral resolution $(40 \mu \mathrm{m})$ used in the present LIBS experiments is not capable to fully resolve zoning features of the smaller mineral grains investigated, the effect can still influence the LIBS spectra collected at various locations and depths. Therefore, the extent of heterogeneity of the mineral grains in the samples was first investigated by repeated measurements.

Individual LIBS spectra were collected from 10 shots delivered at 4-5 locations within each mineral grain. LIBS data from the first shot ("cleaning shot") were discarded and data from 9 depth levels were retained. Spectra within each mineral across locations or depths (intra-mineral variations) were then 
compared to each other using the linear correlation function, which indicates full similarity with a Pearson correlation coefficient value of 1 , and full dissimilarity with a value of 0 (assuming positive intensities). ${ }^{55,56}$ Ray plots in Fig. 2 show the observed intra-mineral variations of each mineral grain in sample M1.

It was generally found that there is a reasonable similarity of spectra, indicated by correlation factors of at least 0.85 in most cases. It can also be seen that the inter-location (lateral) variations, or heterogeneities, are significantly larger than the interdepth variations. This can be attributed to the larger spatial distance between locations (ca. 100-500 $\mu \mathrm{m}, c f$. Fig. 1) than depth levels, which makes location-related changes from the same zone generally more observable. It is also apparent that the LIBS spectra from depth level 1 are quite dissimilar from the rest the depth-resolved data, hence the data not only the first (already discarded) but also from the second laser shot should be considered as a cleaning shot. Based on these observed variations, we decided that in the mineral classification part of our study, we use the depth-averaged LIBS spectra from depths 2-9 of each location in each mineral grain as a statistical data element.

Another observation made in data in Fig. 2 is that zoning in the present samples is most pronounced in quartz and feldspar grains, whereas variations between different grains of the same mineral are also clearly identifiable. These observations should be considered when the accuracy of mineral grain classifications is evaluated in Section 3.3.

\subsection{Laser ablation characteristics of the mineral grains}

The studied minerals are all silicates, but their generalized composition is disparate. ${ }^{53}$ Besides, their colours are also different, hence it can be expected that their laser ablation behaviours are different as well (because of the different light absorption characteristics). To assess this, we investigated the laser ablation craters in the mineral grains by using contact profilometry after delivering ten repeated laser shots under the same conditions as described in the Experimental section. The cross-sectional profilometry curves (Fig. 3) reveal that the crater depths and volumes are indeed highly different, which indicates that quantitative analysis (or certain discriminative analysis) can only be attempted with reasonable accuracy if matrixmatched calibration or at least crater volume normalization (with a general silicate standard, such as the NIST 6XX glass series) is performed. The ablation depth per a laser shot was approximately $1.4 \mu \mathrm{m}$ for quartz, $4 \mu \mathrm{m}$ for biotite and $11 \mu \mathrm{m}$ for feldspar.

\subsection{Qualitative discrimination of mineral grains}

Considering the classification character of the analytical problem addressed here, we tested the performance of mainly multivariate chemometric methods (RF and LDA), which can also be called machine learning (ML) methods. In these methods, we used uncompressed data sets, as in our experience, data compression often leads to a distortion, which in turn may decrease the discrimination power and reliability (robustness) of the classification. This requires chemometric (or ML) methods that can cope with uncompressed data, which is the case with RF and LDA. In addition, we also assessed the performance of a more conventional approach in which the presence of spectral lines of indicator elements (characteristic of the mineral composition) were used for discrimination.

For model construction (training), we used minerals in sample M1. The model then was validated by using it on sample M2 and M3. The accuracy of the methods was established by comparing the predicted and actual mineral types; the accuracy was expressed in terms of correct classifications. Moreover, we give calculated accuracy results according to two approaches:
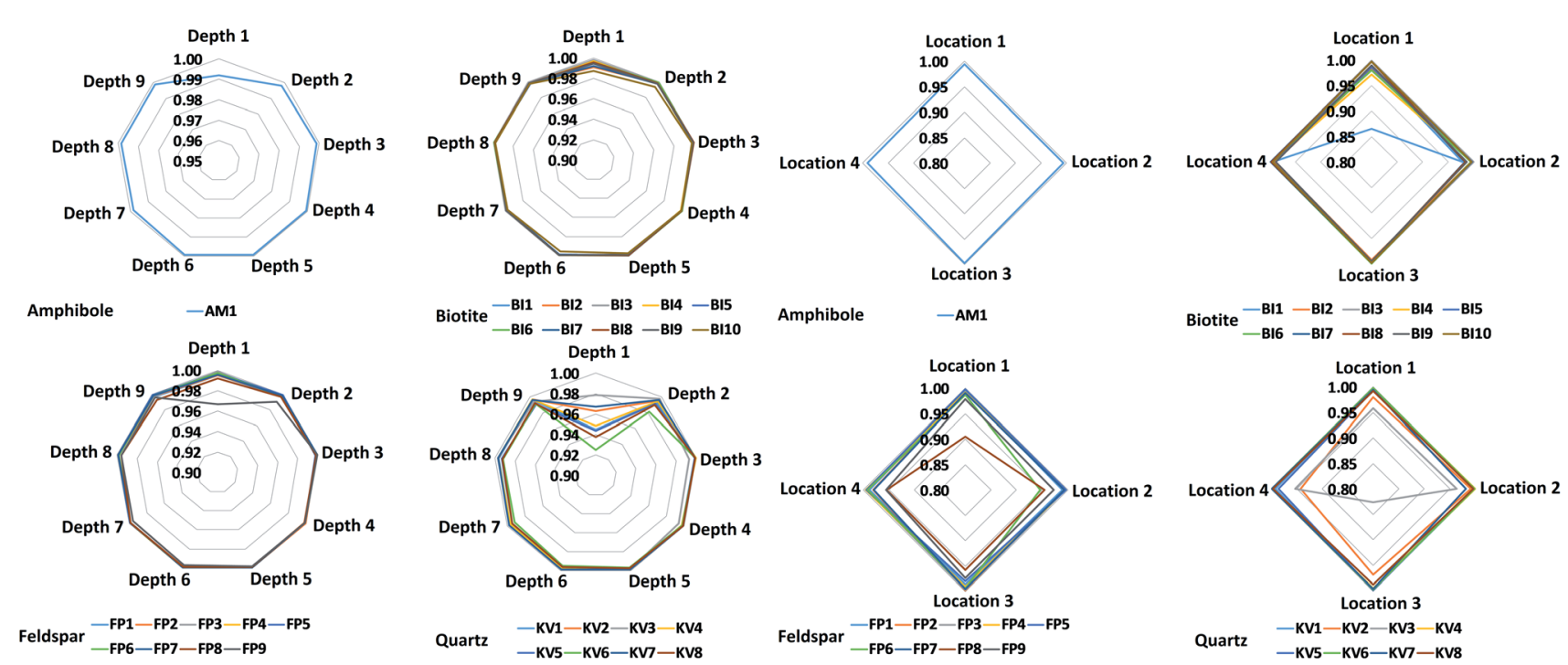

Fig. 2 Intra-mineral compositional variations of each mineral grain in sample M1, as assessed by comparing LIBS spectra taken at various locations and depths by the linear correlation function. The average spectrum across the non-varying coordinate, depth or location, was taken as reference during the comparisons. The ray plots show the correlation coefficient on their radial axes. 

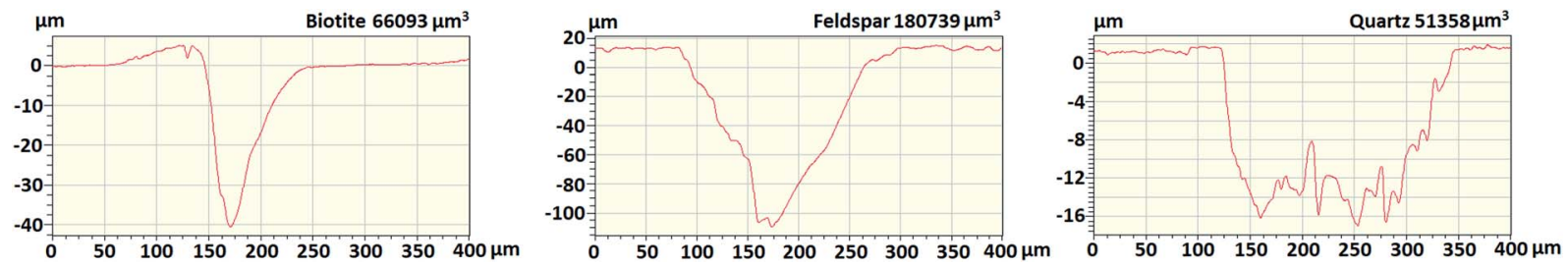

Fig. 3 Ablation crater cross-sections of the mineral grains from ten repeated laser shots, as obtained by contact profilometry. The crater volume is indicated in the upper right corner of each graph.

a location- and a grain-based metric. The grain-based accuracy was obtained in the way that separate laser ablation locations (4-5 within each grains) were evaluated individually and the majority "vote" for the mineral type was associated with that grain. The location-based accuracy was calculated as the overall accuracy obtained when spectra from ablation locations in each grain were evaluated individually.

3.3.1. Classification by using indicative spectral lines. LIBS is a method of elemental analysis, thus one of the obvious potential approaches for the classification of mineral grains is to look for the presence of characteristic (indicative) spectral lines of the elements that make up the minerals. In the present case the nominal composition of the four minerals are $\left[\mathrm{K}(\mathrm{Mg}, \mathrm{Fe})_{3}(\mathrm{Al}, \mathrm{Fe}) \mathrm{Si}_{3} \mathrm{O}_{10}(\mathrm{OH}, \mathrm{F})_{2}\right]$ for biotite, $\left[\mathrm{SiO}_{2}\right]$ for quartz, [NaAlSi $\mathrm{O}_{8}-\mathrm{KAlSi}_{3} \mathrm{O}_{8}-\mathrm{CaAl}_{2} \mathrm{Si}_{2} \mathrm{O}_{8}$ ] for feldspar, and $\mathrm{Na}_{0-1} \mathrm{Ca}_{2}(-$ $\mathrm{Mg}, \mathrm{Fe}, \mathrm{Al})_{5}(\mathrm{Al}, \mathrm{Si})_{8} \mathrm{O}_{22}(\mathrm{OH})_{2}$ for amphibole. ${ }^{53}$ Based on this knowledge, we have set up a simple protocol - essentially a controlled decision tree - for classification. The protocol, shown in Fig. 4, is based on the detection of characteristic major components $\mathrm{Al}, \mathrm{Fe}, \mathrm{K}$ and $\mathrm{Ca}$ via the presence or absence of their selected lines in the LIBS spectrum. Amphibole was actually not involved in this part of this evaluation, because the single grain studied of this mineral is not enough for a statistically relevant evaluation - nevertheless we indicated its position in the decision tree structure.

For the testing of this protocol, the spectral lines of $\mathrm{Al} \mathrm{I}$ $308.21 \mathrm{~nm}$, Fe I $371.99 \mathrm{~nm}$, Ca II $393.37 \mathrm{~nm}$ and K I $769.93 \mathrm{~nm}$ were selected from the NIST Atomic Spectra Database. Each of these spectral lines is free from interference, at the resolution of our LIBS instrument, from the other three elements, as well as from $\mathrm{Si}, \mathrm{O}, \mathrm{Na}$ and $\mathrm{Mg}$, the other commonly occurring components of these minerals. It is essential for the functioning of the protocol that a given element is only considered as present if the intensity of its spectral line exceeds a threshold intensity corresponding to a concentration level that classifies as a major component (e.g. $0.5 \mathrm{~m} / \mathrm{m} \%)$. Corresponding intensity thresholds for the above four spectral lines were taken from calibration plots obtained using the NIST glass (silicate) standards. These four intensity thresholds were then used as initial estimates for the Nelder-Mead simplex optimization algorithm ${ }^{52}$ which was performed to maximize the accuracy of the classification of all mineral grains in sample M1. As described earlier, depth-averaged LIBS spectra taken at each location in each grain were used as statistical elements in this classification. When the simplex algorithm terminated, the optimized intensity thresholds were used to evaluate LIBS data from the mineral grains in samples M2 and M3. A grain was only considered to be accurately identified if the majority of the locations within the grain gave correct identification. As can be seen, the classification is very accurate for biotite and feldspar but is significantly poorer for quartz, for which it is around $80 \%$ only. This result is in line with the former finding, namely that quartz grains are rather impure in the samples. The results also strongly suggest that sampling at several locations within each grain makes the identification more robust. Table 1 gives an overview of the accuracies obtained.

3.3.2. Classification by using random forests. Random forests $(\mathrm{RF})$ is a multivariate method of classification, which can be considered to be the advanced version of the classification (or decision) tree approach. It was recently introduced by Breiman in $2001 .^{49}$ The generally recognized advantages of the RF method includes the ability to work with large datasets (with

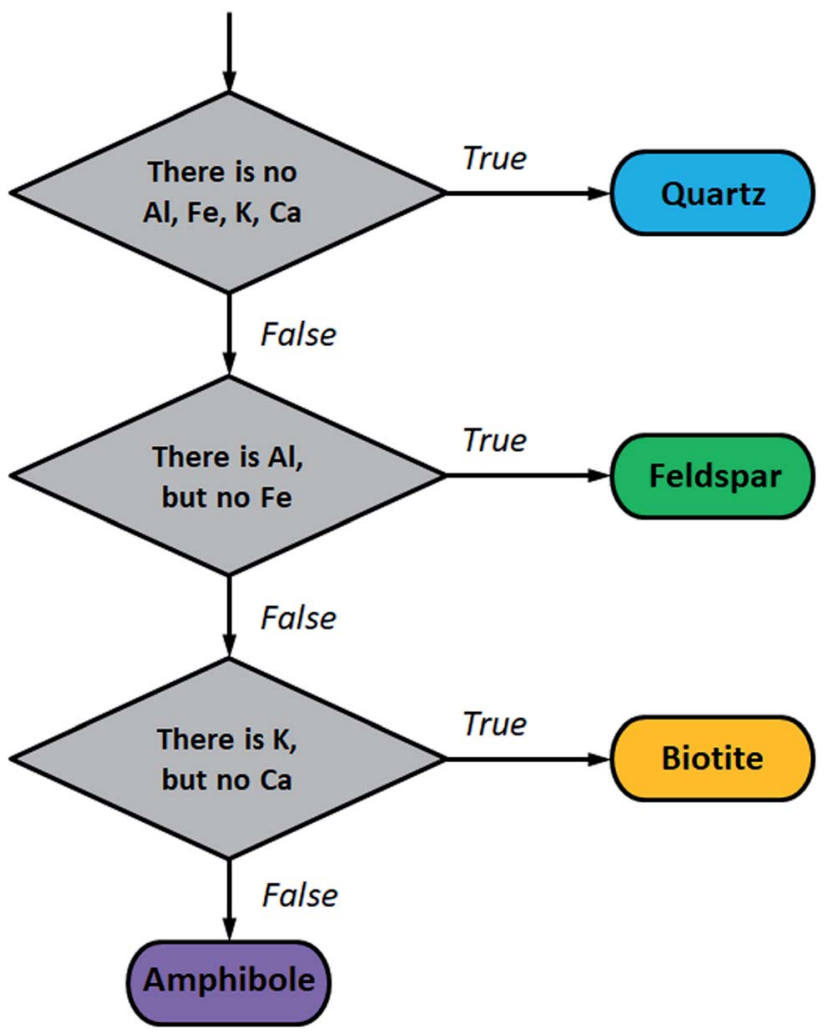

Fig. 4 Flow chart for mineral grain classification based on the LIBS detection of major components $\mathrm{Al}, \mathrm{Fe}, \mathrm{K}$ and $\mathrm{Ca}$. 
Table 1 The overall accuracy of the classification of minerals in all three rock samples according to the three employed statistical methods. The grain-based accuracy is based on the majority "vote" for the mineral type from all sampling locations within the grain. Location-based accuracy was calculated as the overall accuracy when spectra from ablation locations in each grain were evaluated individually

\begin{tabular}{|c|c|c|c|c|c|c|}
\hline & \multicolumn{2}{|l|}{ Indicator lines } & \multicolumn{2}{|c|}{ Random forest (RF) } & \multicolumn{2}{|c|}{ Linear discriminant analysis (LDA) } \\
\hline & $\begin{array}{l}\text { As per sampling } \\
\text { locations }\end{array}$ & As per grains & $\begin{array}{l}\text { As per sampling } \\
\text { locations }\end{array}$ & As per grains & $\begin{array}{l}\text { As per sampling } \\
\text { locations }\end{array}$ & As per grains \\
\hline Biotite & $97.60 \%$ & $100.00 \%$ & $95.30 \%$ & $97.00 \%$ & $95.30 \%$ & $97.00 \%$ \\
\hline Feldspar & $95.50 \%$ & $100.00 \%$ & $88.40 \%$ & $92.60 \%$ & $89.00 \%$ & $92.60 \%$ \\
\hline Quartz & $80.70 \%$ & $77.30 \%$ & $84.30 \%$ & $95.40 \%$ & $87.90 \%$ & $95.40 \%$ \\
\hline
\end{tabular}

thousands of variables), good accuracy and fast computation. Random forests have recently been successfully used in LIBS sample discrimination studies e.g. on polymers, ${ }^{57}$ ceramics, ${ }^{58}$ steel samples ${ }^{59}$ and iron ores. ${ }^{60}$

In the present application, we trained the RF with datasets on sample M1 and optimized the number of trees as well as the number of nodes. Up to 500 trees with up to 20 nodes were evaluated by monitoring the out-of-bag error. It was found that the OOB initially steeply decreases with the increase in the number of trees and asymptotically reaches its minimum at around 50. Simultaneously, the increase of the number of nodes clearly deteriorated the OOB; the minimum was found with as little as two nodes. All RF classification results were therefore obtained by using 100 trees with two nodes.

As can be seen in Table 1, RF gave good, well-balanced results. The accuracy for grain-based classification was at least 92.6\% for all three minerals. Similarly to the indicator line approach, the grain-based accuracy (majority vote of sampling locations within the grain) was better than when classification by each sampling locations was considered. By scrutinizing the nodes, it is also possible to estimate the most important (most frequent) classifiers. This analysis interestingly revealed that $274.29 \mathrm{~nm}, 400.84 \mathrm{~nm}, 345.65 \mathrm{~nm}$ and $326.08 \mathrm{~nm}$ were these variables, which may be associated with Fe, Th and V, instead of major components of the rock-forming minerals.

3.3.3. Classification by using linear discriminant analysis. Linear discriminant analysis (LDA), also known as discriminant function analysis, is a widely employed classification technique. ${ }^{51}$ It generally performs well in LIBS classification studies done on various samples, including rocks, ${ }^{\mathbf{1 0 , 3 4 , 6 1 , 6 2}}$ although it is known to give unstable results if multicollinearity is present in the data set.

We tested Bayesian LDA on our uncompressed LIBS data. The results can be seen in Table 1 and Fig. 5. The overall classification accuracy was good, over $87 \%$ based on separate sampling locations and over $92 \%$ for grains (based on the majority vote within a grain). False classifications can be mostly associated with quartz and feldspar.

\subsection{Quantitative assessment of the distribution of selected trace elements}

3.4.1. Mapping of Be and Li. Considering their relevance, we collected LIBS elemental maps of $\mathrm{Be}$ and $\mathrm{Li}$ in granitoid sample M1. Step scanning with non-overlapping laser spots (resolution: $40 \mu \mathrm{m}$, laser pulse energy: $5 \mathrm{~mJ}$ ) was employed in this part of the investigation. Spectral intensity-based elemental

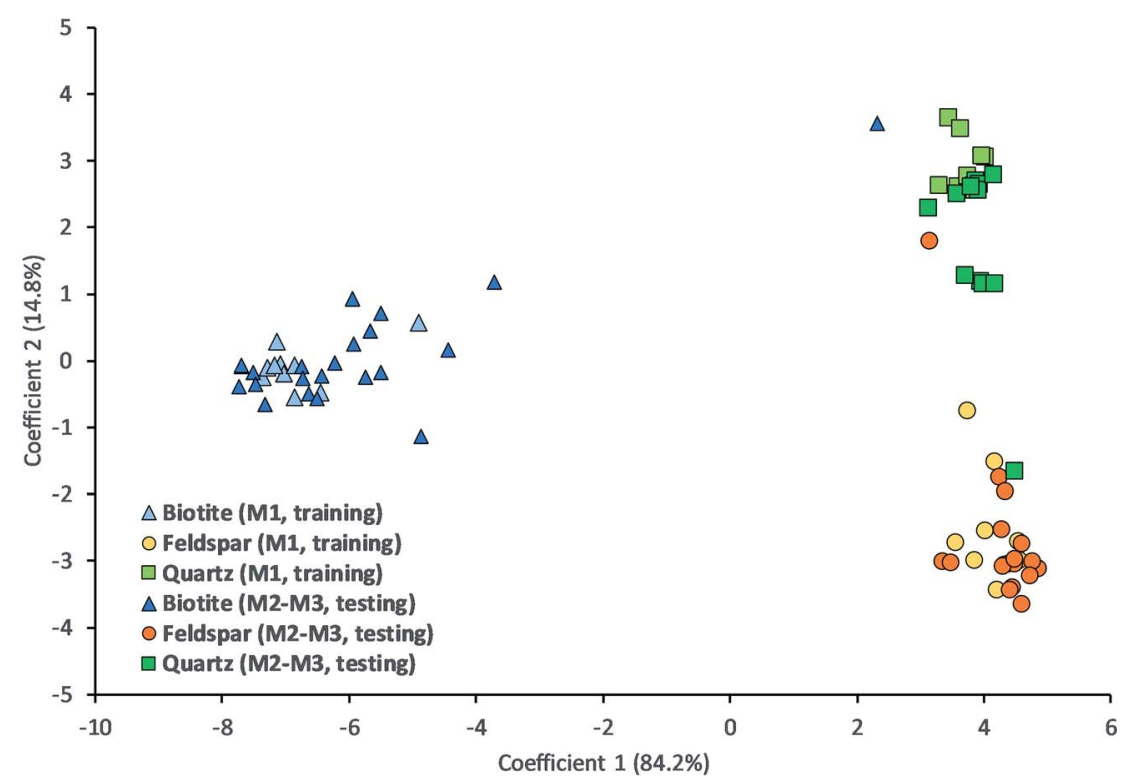

Fig. 5 Biplot of the LDA classification results of the mineral grains. 
maps for Be II $313.0 \mathrm{~nm}$ and $\mathrm{Li}$ I $670.7 \mathrm{~nm}$ lines can be seen in Fig. 6. Besides other uses proposed recently in the literature for such LIBS elemental maps, such as grain boundary ${ }^{\mathbf{4 2}}$ or grain size determination, ${ }^{63}$ here we demonstrate that it is possible to identify the type of mineral that contains most of the targeted trace elements. By the comparison of Fig. 6 and 1, it can be realized that biotite and amphibole grains contain the most $\mathrm{Li}$ and Be, whereas feldspar has significantly lower amounts of both elements. $\mathrm{As} \mathrm{Li}^{+}$has a cation radius rather close to that of $\mathrm{Mg}^{2+}$, in most crystal lattices $\mathrm{Li}$ incorporates to the position occupied by $\mathrm{Mg}$. Among the studied phases, biotite and amphibole are the minerals where the $\mathrm{Mg} \leftrightarrow \mathrm{Li}$ exchange is possible. Similarly, due to the close geochemical behaviour of $\left[\mathrm{BeO}_{4}\right]^{6-}$ with $\left[\mathrm{AlO}_{4}\right]^{5-}$, beryllium can replace aluminum in most silicate structures, like in the feldspar and mica (biotite) lattices. As there is no exchangeable cation in its structure, not surprisingly, quartz has the least traces of these metals. The distribution of Be and $\mathrm{Li}$ among the grains seem to be qualitatively correlated. These results suggest that mining for Be and Li in granitoid rocks should be aiming for biotite and amphibole grains. A promising approach for such a mining activity may be the ISL (in situ leaching) technique, which is being intensively developed recently. ${ }^{64}$

3.4.2. Quantitative estimation of the $\mathrm{Be}$ and $\mathrm{Li}$ content. Intensity-based elemental maps provide limited information for prospecting purposes, therefore we also performed calculations to quantitatively assess the $\mathrm{Be}$ and $\mathrm{Li}$ content in the mineral grains of samples M1 to M3 (only considering those biotite, feldspar and quartz grains which were identified in Fig. 1.). Net intensity data for the Li I $670.7 \mathrm{~nm}$ and Be II $313.0 \mathrm{~nm}$ spectral lines collected at the measurement locations indicated in Fig. 1 were converted to concentrations by calibration using matrixmatched standards. The NIST 612 standard was used for quartz calibration based on their similar laser ablation behaviour (similar crater volumes). The average of the 4-5 concentration data obtained within each grain was assigned to that grain and then the surface area of the grain, determined by the ImageJ software, and the typical density value of the mineral was used to convert this to the mass of Be and Li present in each grain. We assumed an arbitrary, uniform $100 \mu \mathrm{m}$ "depth" value during the volume determination; this value is roughly the average grain diameter in our sectioned samples - a better estimation for the individual grain volumes was not available. The results are summarized in Fig. 7 and reveal that ng to $\mu \mathrm{g}$ amounts of the metals could be quantitatively determined by LIBS. On the left panel of the figure the metal contents expressed in mass, and on the right panel in concentration, can be observed.

Data in Fig. 7 justify the assumption suggested by the intensity-based elemental maps namely that the $\mathrm{Li}$ and $\mathrm{Be}$ content varies concertedly in all three minerals - the pattern show that generally (with very rare exceptions) wherever the $\mathrm{Li}$ content is high, so is the Be content. The mass of the metals present in the grains naturally changes with the size of the grain, thus the concentration distribution does not follow the same pattern, but the relative contents of Be and Li follow the same trend. Be concentrations (amounts) are in the same magnitude as Li concentrations (amounts) in quartz and feldspar, whereas they are significantly different in biotite, in which Li concentrations are almost one hundred times higher than those of Be. Not surprisingly, quartz contains the smallest amounts of both metals. It is also apparent that feldspar is the best source of $\mathrm{Be}$, whereas biotite is for Li. According to the relevant report published by the Geological Institute of Hungary, the mineral composition of Mórágy Granite samples is $10 \%$ biotite, $70 \%$ feldspar and 15\% quartz, with the remaining $5 \%$ being mostly amphibole. ${ }^{65}$ Using this average mineral composition data, an estimate can be given for the overall Be and $\mathrm{Li}$ content of these rocks: $1 \mathrm{~kg}$ of these rocks contain $\mathrm{ca}$. $28 \mathrm{mg}$ of Be and $144 \mathrm{mg}$ of $\mathrm{Li}$.

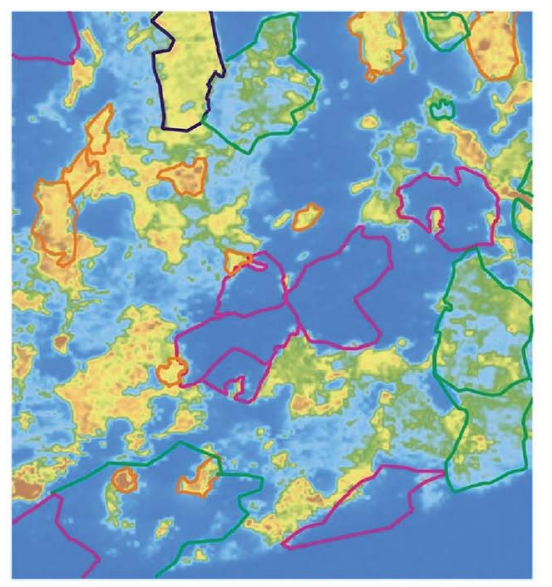

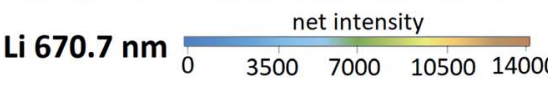

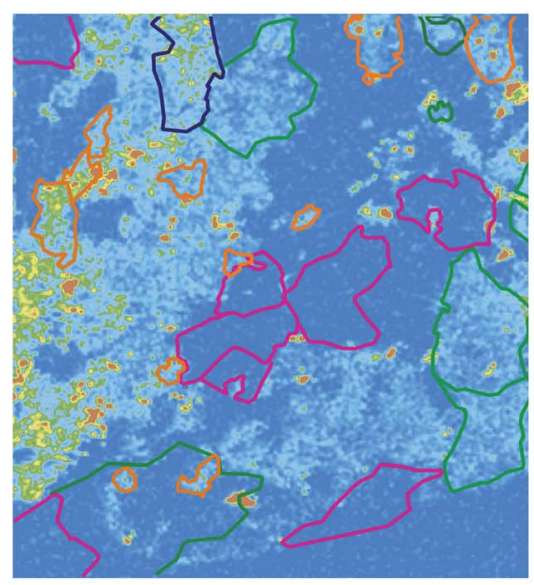

$\begin{array}{lllll} & \text { net intensity } & \\ & 513.0 & 100 \quad 150 \quad 200\end{array}$

Biotite

Fig. 6 Intensity-based step-scan LIBS elemental maps of the M1 sample. Colors of the contours are indicating the mineral types, as seen in Fig. 1. 

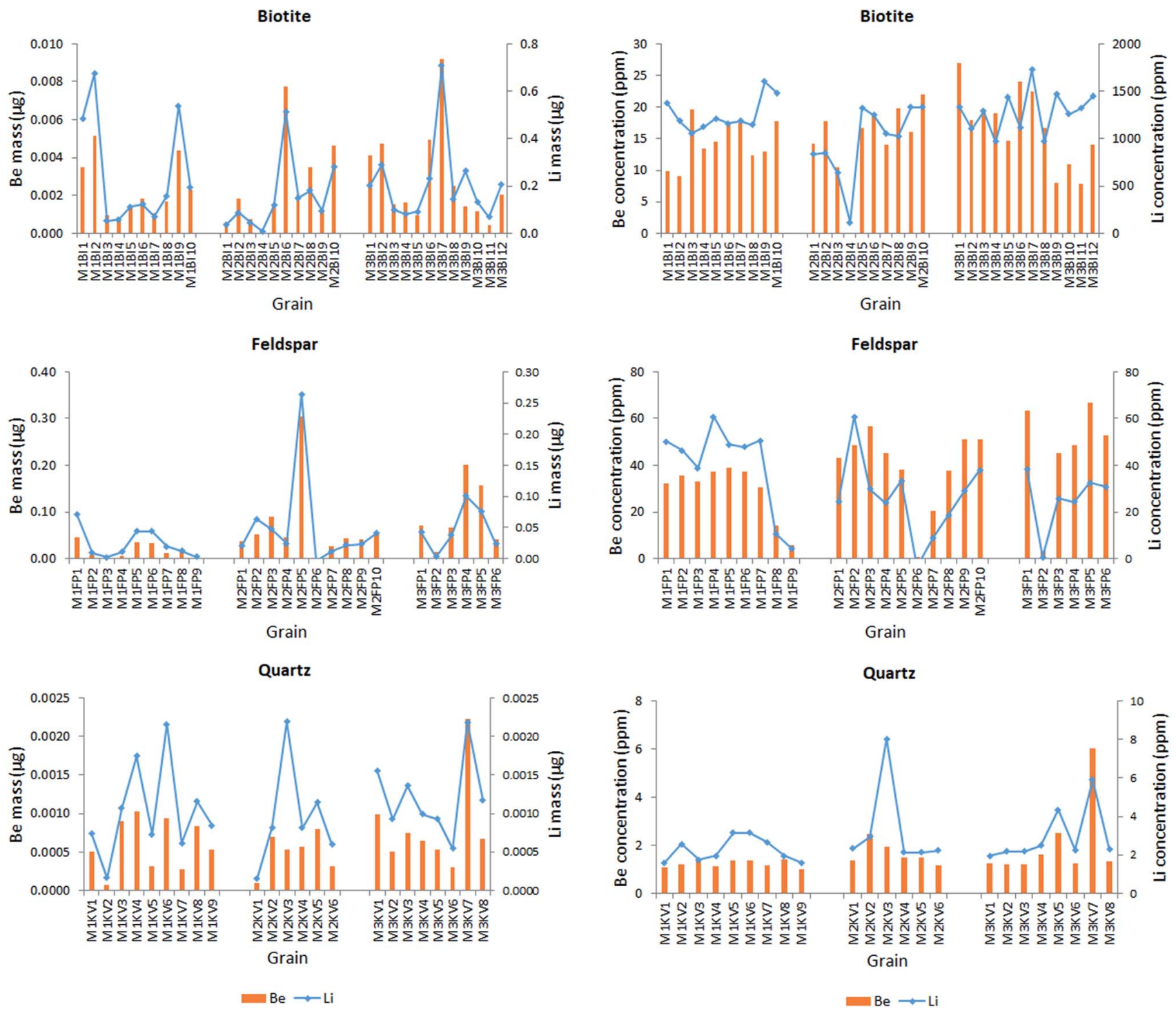

Fig. 7 The Li and Be content of each analyzed mineral grain, expressed in terms of mass (on the left) and ppm concentration (on the right).

\section{Conclusions}

We have shown that LIBS mapping and spatially resolved local analysis is an efficient and practical approach for the classification of mineral grains (quartz, feldspar, biotite, amphibole) and for prospecting of technologically relevant elements in granitoid rock samples. We have tested three statistical approaches for the classification and it was demonstrated that better than $92 \%$ classification accuracy is achievable by using random forests and linear discriminant analysis. Direct classification by assessing the presence of the characteristic elements (decision tree based on indicative spectral lines) is a powerful method but can lead to great failure rates in case of relatively pure minerals, such as quartz. Our results also revealed that using multiple analytical locations within each grain and resting the classification on the majority vote of these individual analysis gives more reliable discrimination. We also demonstrated that LIBS elemental mapping can provide valuable information about the distribution of chemical elements in the minerals, especially if it is combined with the matrix-matched calibration of emission intensity data.

It is also worth emphasizing that the appeals of LIBS in this and similar geochemical and mining industry-oriented applications include that it is a highly versatile analytical technique which is portable, robust, can be used in a stand-off situation and is equally sensitive to light and heavy elements. This is a unique set of features among atomic spectroscopy techniques. In our opinion, the sensitivity of the technique is well demonstrated by the fact that we successfully assessed $\mathrm{ng}$ to $\mu \mathrm{g}$ amounts of $\mathrm{Be}$ and $\mathrm{Li}$ in the studied mineral grains. We also point out that the described LIBS analytical and data evaluation approaches can be potentially fairly easily generalized and automated. For example, once grain boundaries in a rock sample are automatically identified by modern computer vision and machine learning methods (e.g. ref. 42), spatially resolved LIBS analysis can identify the mineral types and use this 
information to select the proper calibration standards (calibration curves) that can be used to convert spectral intensity data to concentration (mass) data of relevant elements.

\section{Conflicts of interest}

There are no conflicts to declare.

\section{Acknowledgements}

The financial support received from various sources including the Ministry of Innovation and Technology (through project no. TUDFO/47138-1/2019-ITM FIKP and Tématerületi Kiválósági Program TKP 2020) and the National Research, Development and Innovation Office (through projects no. K_129063, EFOP3.6.2-16-2017-00005 and GINOP-2.3.3-15-2016-00040) of Hungary is kindly acknowledged.

\section{References}

1 G. Galbács, Anal. Bioanal. Chem., 2015, 407, 7537-7562.

2 F. J. Fortes, J. Moros, P. Lucena, L. M. Cabalin and J. J. Laserna, Anal. Chem., 2013, 85, 640-669.

3 D. W. Hahn and N. Omenetto, Appl. Spectrosc., 2012, 66, 347419.

4 N. Jedlinszki and G. Galbács, Microchem. J., 2011, 97, 255263.

5 A. Bol'shakov, X. Mao, J. J. González and R. E. Russo, J. Anal. At. Spectrom., 2016, 31, 119-134.

6 A. Metzinger, R. Rajkó and G. Galbács, Spectrochim. Acta, Part $B, 2014,94,48-57$.

7 J. Moros, J. Serrano, C. Sanchez, J. Macias and J. J. Laserna, J. Anal. At. Spectrom., 2012, 27, 2111-2122.

8 S. Manzoor, S. Moncayo, F. Navarro-Villoslada, J. A. Ayala, R. Izquierdo-Hornillos, F. J. Manuel de Villena and J. O. Caceres, Talanta, 2013, 121, 65-70.

9 A. M. Ollila, J. Lasue, H. E. Newsom, R. A. Multari, R. C. Wiens and S. M. Clegg, Appl. Opt., 2012, 51, B130-B142.

10 D. J. Palásti, A. Metzinger, T. Ajtai, Z. Bozóki, B. Hopp, É. Kovács-Széles and G. Galbács, Spectrochim. Acta, Part B, 2019, 153, 34-41.

11 G. Vitkova, K. Novotny, L. Prokes, A. Hrdlicka, J. Kaiser, J. Novotny, R. Malina and D. Prochazka, Spectrochim. Acta, Part B, 2012, 73, 1-6.

12 J. Klus, P. Mikysek, D. Prochazka, P. Pořízka, P. Prochazková, J. Novotný, T. Trojek, K. Novotný, M. Slobodník and J. Kaiser, Spectrochim. Acta, Part B, 2016, 123, 143-149.

13 V. K. Singh, J. Sharma, A. K. Pathak, C. T. Ghany and M. A. Gondal, Biophys. Rev., 2018, 10, 1221-1239.

14 L. Wanting, L. Xiangyou, L. Xin, H. Zhongqi, L. Yongfeng and Z. Xiaoyan, Appl. Spectrosc. Rev., 2020, 55, 1-25.

15 R. S. Harmon, C. J. Lawley, J. Watts, C. L. Harraden, A. M. Somers and R. R. Hark, Minerals, 2019, 9, 718.

16 R. S. Harmon, R. E. Russo and R. R. Hark, Spectrochim. Acta, Part B, 2013, 87, 11-26.
17 J. D. Winefordner, I. B. Gornushkin, T. L. Correll, E. Gibb, B. W. Smith and N. Omenetto, J. Anal. At. Spectrom., 2004, 19, 1061-1083.

18 S. Qiao, Y. Ding, D. Tian, L. Yao and G. Yang, Appl. Spectrosc. Rev., 2015, 50, 1-26.

19 T. F. Boucher, M. V. Ozanne, M. L. Carmosino, M. D. Dyar, S. Mahadevan, E. A. Breves, K. H. Lepore and S. M. Clegg, Spectrochim. Acta, Part B, 2015, 107, 1-10.

20 M. D. Dyar, M. L. Carmosino, E. A. Breves, M. V. Ozanne, S. M. Clegg and R. C. Wiens, Spectrochim. Acta, Part B, 2012, 70, 51-67.

21 N. J. McMillan, C. E. McManus, R. S. Harmon, F. C. Lucia Jr and A. W. Miziolek, Anal. Bioanal. Chem., 2006, 385, 263-271.

22 N. J. McMillan, R. S. Harmon, F. C. De Lucia and A. M. Miziolek, Spectrochim. Acta, Part B, 2007, 62, 15281536.

23 D. L. Death, A. P. Cunningham and L. J. Pollard, Spectrochim. Acta, Part B, 2009, 64, 1048-1058.

24 Q. Sun, M. Tran, B. W. Smith and J. D. Winefordner, Anal. Chim. Acta, 2000, 413, 187-195.

25 M. Gaft, I. Sapir-Sofer, H. Modiano and R. Stana, Spectrochim. Acta, Part B, 2007, 62, 1496-1503.

26 J. Cunat, S. Palanco, F. Carrasco, M. D. Simon and J. J. Laserna, J. Anal. At. Spectrom., 2005, 20, 295-300.

27 G. Galbács, I. Kevei-Bárány, E. Szőke, N. Jedlinszki, I. B. Gornushkin and M. Z. Galbács, Microchem. J., 2011, 99, 406-414.

28 K. M. Abedin, A. F. M. Y. Haider, M. A. Rony and Z. H. Khan, Opt. Laser Technol., 2011, 43, 45-49.

29 Y. Hu, Z. Li and T. Lü, J. Anal. At. Spectrom., 2017, 32, 22632270.

30 M. A. Gondal, M. M. Nasr, Z. Ahmed and Z. H. Yamani, J. Environ. Sci. Health, Part A: Toxic/Hazard. Subst. Environ. Eng., 2009, 44, 528-535.

31 P. K. Srungaram, K. K. Ayyalasomayajula, F. Yu-Yueh and J. P. Singh, Spectrochim. Acta, Part B, 2013, 87, 108-113.

32 C. Fabre, M.-C. Boron, J. Dubessy, M. Cathlineau and D. Banks, Chem. Geol., 2002, 182, 249-264.

33 L. Zhang, Z. Hu, W. Yin, D. Huang, W. G. Ma, D. Lei, H. P. Wu, Z. X. Li, L. T. Xiao and S. T. Jia, Front. Phys., 2012, 7, 690-700.

34 A. Metzinger, D. J. Palásti, É. Kovács-Széles, T. Ajtai, Z. Bozóki, Z. Kónya and G. Galbács, Energy Fuels, 2016, 30, 10306-10313.

35 P. Pořízka, A. Demidov, J. Kaiser, J. Keivanian, I. Gornushkin, U. Panne and J. Riedel, Spectrochim. Acta, Part B, 2014, 101, 155-163.

36 S. M. Clegg, E. Sklute, M. D. Dyar, J. E. Barefield and R. C. Wiens, Spectrochim. Acta, Part B, 2009, 64, 79-88.

37 R. S. Harmon, J. J. Remus, C. McManus, F. C. DeLucia, J. Gottfried and A. W. Miziolek, Appl. Geochem., 2009, 24, 1125-1141.

38 J. L. Gottfried, R. S. Harmon, F. C. De Lucia and A. W. Miziolek, Spectrochim. Acta, Part B, 2009, 64, 10091019. 
39 D. C. Alvey, K. Morton, R. S. Harmon, J. L. Gottfried, J. J. Remus, L. M. Collins and M. A. Wise, Appl. Opt., 2010, 49, C168-C180.

40 J. J. Remus, R. S. Harmon, R. R. Hark, G. Haverstock, D. Baron, I. K. Potter, S. K. Bristol and L. J. East, Appl. Opt., 2012, 51, B65-B73.

41 R. S. Harmon, K. M. Shughrue, J. J. Remus, M. A. Wise, L. J. East and R. R. Hark, Anal. Bioanal. Chem., 2011, 400, 3377-3382.

42 J. A. Meima and D. Rammlmair, Chem. Geol., 2020, 532, 119376.

43 A. Nardecchia, C. Fabre, J. Cauzid, F. Pelascini, V. Motto-Ros and L. Duponchel, Anal. Chim. Acta, 2020, 1114, 66-73.

44 S. Kalantzakos, China and the Geopolitics of Rare Earths, Oxford University Press, New York, 1st edn, 2017.

45 Raw materials scoreboard: European innovation partnership on raw materials, 2018, https://op.europa.eu/en/publicationdetail/-/publication/117c8d9b-e3d3-11e8-b69001aa75ed71a1, accessed 24 September 2020.

46 A Magyar Állami Földtani Intézet Évi Jelentése, 2004, http:// epa.oszk.hu/02900/02934/00031/pdf/

EPA02934_mafi_evi_jelentes_2004_041-064.pdf, accessed 24 September 2020.

47 Z. Kercsmár, T. Budai, G. Csillag, I. Selmeczi and O. Sztanó, Magyarország felszíni képződményeinek földtana, Magyar Földtani és Geofizikai Intézet, Budapest, 1st edn, 2015.

48 J. D. Winter, Principles of igneous and metamorphic petrology, Pearson Education Limited, London, 2nd edn, 2014.

49 L. Breiman, Mach. Learn., 2001, 45, 5-32.

50 L. Breiman and A. Cutler, Random forest, 2020, https:// www.stat.berkeley.edu/ breiman/RandomForests/ cc_home.htm, accessed 24 September 2020.
51 K. Varmuza and P. Filzmoser, Introduction to Multivariate Statistical Analysis in Chemometrics, CRC Press, Taylor \& Francis Group, New York, 1st edn, 2009.

52 J. A. Nelder and R. Mead, Comput. J., 1965, 7, 308-313.

53 W. D. Nesse, Introduction to Mineralogy, Oxford University Press, New York, 1st edn, 2000.

54 M. J. Streck, Rev. Mineral. Geochem., 2008, 69, 595-622.

55 G. Galbács, I. B. Gornushkin, B. W. Smith and J. D. Winefordner, Spectrochim. Acta, Part B, 2001, 56, 1159-1173.

56 G. Galbács, I. B. Gornushkin and J. D. Winefordner, Talanta, 2004, 63, 351-357.

57 L. Brunnbauer, S. Larisegger, H. Lohninger, M. Nelhiebel and A. Limbeck, Talanta, 2020, 209, 120572.

58 J. Qi, T. Zhang, H. Tang and H. Li, Spectrochim. Acta, Part B, 2018, 149, 288-293.

59 T. Zhang, D. Xia, H. Tang, X. Yang and H. Li, Chemom. Intell. Lab. Syst., 2016, 157, 196-201.

60 L. Sheng, T. Zhang, G. Niu, K. Wang, H. Tang, Y. Duand and H. Li, J. Anal. At. Spectrom., 2015, 30, 453-458.

61 G. Vítková, L. Prokeš, K. Novotný, P. Pořízka, J. Novotný, D. Všianský, L. Čelko and J. Kaiser, Spectrochim. Acta, Part $B$, 2014, 101, 191-199.

62 W. T. Li, Y. N. Zhu, X. Li, Z. Q. Hao, L. B. Guo, X. Y. Li, X. Y. Zenga and Y. F. Lu, J. Anal. At. Spectrom., 2020, 35, 1486.

63 F. Rivera-Hernández, D. Y. Sumner, N. Mangold, K. M. Stack, O. Fornie, H. Newsomg, A. Williams, M. Nachon, J. L'Haridon, O. Gasnault, R. Wiens and S. Maurice, Icarus, 2019, 321, 82-98.

64 W. P. Geddes, Energy Explor. Exploit., 1983, 3, 197-218.

65 V. A. Utenkov, Z. Balla and E. Sallay, Annual Report of the Geological Institute of Hungary 2000-2001, 2003, vol. 1, pp. 153-188. 